\title{
THE EFFECT OF ADDING NATURAL MATERIALS WASTE ON THE MECHANICAL PROPERTIES AND WATER ABSORPTION OF EPOXY COMPOSITE USING GREY RELATIONS ANALYSIS
}

\author{
Ahmad A. Khalaf \\ Department of Mechanical ${ }^{1}$ \\ Salwa A. Abed $\bowtie$ \\ Department of Mechanical ${ }^{1}$ \\ D.salwaabbas@mtu.edu.iq \\ Saad Sami Alkhfaji \\ Department of Medical Instrumentation Engineering \\ Ashur University College \\ Baghdad, Iraq, 10047 \\ Mudhar A. Al-Obaidi \\ Department of Computer Science ${ }^{1}$ \\ Muammel M. Hanon \\ Mechanical Engineering Doctoral School \\ Hungarian University of Agriculture and Life Sciences (MATE) \\ Szent Istvan Campus, Godollo, Hungary, 2100 \\ ${ }^{1}$ Baquba Technical Institute \\ Middle Technical University \\ Opposite Diyala Stadium, Baquba, Diyala, Iraq, 32001
}

$\triangle$ Corresponding author

\section{Abstract}

Recently, there has been a tendency for scientific studies to deal with natural materials as fillers and reinforcement for polymer composites, which are used in many different applications due to their environmentally friendly properties when compared to synthetic materials. The current study aims to preserve the environment by dealing with natural materials and their influence on the mechanical properties and water absorption property of the polymer composites. In this study, epoxy composites were produced from local natural sourced non-hazardous raw natural materials using grey relational analysis (GRG). The materials used for fabrication include micro-filler of pollen palm $50 \mu \mathrm{m}$, seashell $75 \mu \mathrm{m}$ and epoxy resin. Nine different composites were prepared using pollen palm and seashell as reinforcement material by varying the $\mathrm{wt} \%$ of the micro-filler. Rule of the mixture was used for formulation and wt \% of $(0.5,1$ and 1.5$) \%$ reinforcement and 99.5, 99 and $98.5 \%$ epoxy (binder) were used for composites. Grey relational analysis was conducted in order to scale the multi-response performance to a single response. The results indicate that optimum performance can be achieved with the addition of $1.5 \mathrm{wt} \%$ micro-filler of seashell, which achieved the first rank, while the second rank achieved by $0.5 \mathrm{wt} \%$ micro-filler of palm pollen and seashell when compared to other composites. The addition of micro-fillers has improved greatly the mechanical properties of epoxy composites. The loading of micro-fillers has influenced the water absorption property of composites based epoxy in ascending order.

Keywords: epoxy composite, natural material micro-filler, Mechanical properties, Water absorption, GRG.

DOI: $10.21303 / 2461-4262.2022 .001952$

\section{Introduction}

At recent days, there is a great interest from several associations and researchers in employing the natural materials like cellulose nanofibers and seashell in the composites industry. This is due to their excellent mechanical properties of good biodegradability, renewability, low cost, and availability besides low thermal coefficient. Specifically, cellulose being a plentiful natural fiber on 
earth, has been investigated in different fields where numerous researchers progressively focused on cellulose fiber reinforced polymer composites. Consequently, cellulose has been approved as one of the best natural materials to synthesis both plastic and thermosetting polymers [1-3]. In this respect, natural fillers such as oil palm [4, 5] and seashell filler [6] have been successfully used as filler reinforced polymer composites. A state-of-the-art of deploying natural fillers to reinforce polymer composites are addressed in the following: there are other studies that evaluated the effect of adding different types of shells (mollusk shells) as fillers on the mechanical properties of polymer compounds. Density treated mollusk shell granules reinforced with polyethylene. The results showed that the tensile modulus was increased by about $10 \%$ for the compounds of $2 \mathrm{wt} \%$ and $8 \mathrm{wt} \%$ [7, 8].

The influence of adding bamboo cellulose fiber treated with $\mathrm{NaOH}$ solution and silane couple agent was evaluated by $\mathrm{Lu} \mathrm{T}$. et al. on mechanical behavior of cellulose reinforced epoxy composites. The tensile strength and elongation at break of cellulose reinforced epoxy composite were increased by $34 \%$ and $31 \%$, respectively, after treated bamboo fiber with $\mathrm{NaOH}$. However, primitive increases of $71 \%$ and $53 \%$ were noticed for the tensile strength and elongation at break, respectively, after treated bamboo fiber with silane coupling agent [9].

The mechanical properties and water absorption of epoxy composites reinforced with synthetic cellulose/treated fibers were studied and the results showed an improvement in tensile strength of treated fibers compared to untreated fibers [10].

Another study evaluated the mechanical properties and water absorption of Luffa fiber-reinforced polyester composite with and without increasing the fine fillers of $\mathrm{AL}_{2} \mathrm{O}_{3}, \mathrm{CaCO}_{3}$ and $\mathrm{TiO}_{3}$. This study, in turn, showed that increasing micro-fills would improve the physical and mechanical properties of Luffa fiber-based composites [11].

In another study, it was shown that the bending modulus of polymers can be increased by more than $37 \%$, when low content of mollusc shell waste (MSW) and fine particles is added [12].

The above literature confirm a widely spread of using natural fiber reinforced polymer composites in many applications compared to synthetic fiber based polymer composites. Up to the knowledge of the authors, the application of wood residues of pollen palm filler (P. P. F) and seashell filler (S. S. F) as bio-fillers for epoxy polymer bio-composites has not been critically explored yet. In this regard, there are many studies confirming the importance and necessity of maintaining a clean environment through the use of new compounds from materials that are easy to recycle [13, 14].

Iraq ranks high among the palm-growing countries. Based on the report issued by the Iraqi Directorate of Agricultural Statistics for the year 2019, the total number of palm trees produced in all governorates of Iraq is estimated at 17,036,560 palm trees, and the number of females is 16514834 while the number of males is 521,726. It is known that the pollen grains of one palm tree are enough to pollinate 50 to 100 female palm [15]. Based on the above statistics, it is evident that there is a waste in not benefiting from pollen palm for an estimated 330297 to 165148 male palm trees. Therefore, this study focuses on preparing micro-filler of seashell-waste and pollen palm/epoxy composites with two different grades of $75 \mu \mathrm{m}$ and $50 \mu \mathrm{m}$, respectively. Mechanical properties and water absorption of three different types of composites composed of pollen palm filler only, composite composed of seashell filler only and composite composed of mixture of both fillers were investigated. The ranking of as fabricated epoxy composites has been made by Grey Relational Analysis method on the mechanical properties and water absorption. Interestingly, this study has the new environment friendly composites produced from recycled natural material with low cost.

\section{Materials and method}

\section{1. Materials}

The resin used in this work is epoxy with hardener type sika-dur32 and density of $1.1 \mathrm{~kg} / \mathrm{L}$. Snail seashell was collected from the Mitterrand Coast. The chemical composition of seashell filler is as follows; $19.79 \mathrm{wt} \% \mathrm{C}, 47.98 \mathrm{wt} \% \mathrm{O}, 041 \mathrm{wt} \% \mathrm{Na}, 0.25 \mathrm{wt} \% \mathrm{Mg}, 0.09 \mathrm{wt} \% \mathrm{Al}, 31.11 \mathrm{wt} \%$ $\mathrm{Ca}$ and $0.38 \mathrm{wt} \% \mathrm{Cu}$. The pollen palm type Zahdi was collected from orchards of the Shifta village/Baqubaa city/Diyala/Iraq and its chemical composition is as follows; $1.4 \mathrm{wt} \%$ fiber, $21.5 \mathrm{wt} \%$ fat, $32 \mathrm{wt} \%$ protein, $14 \mathrm{wt} \%$ carbohydrate and various Vitamins. Fig. 1 shows the snaps of micro-bio fillers of pollen palm and seashell. 


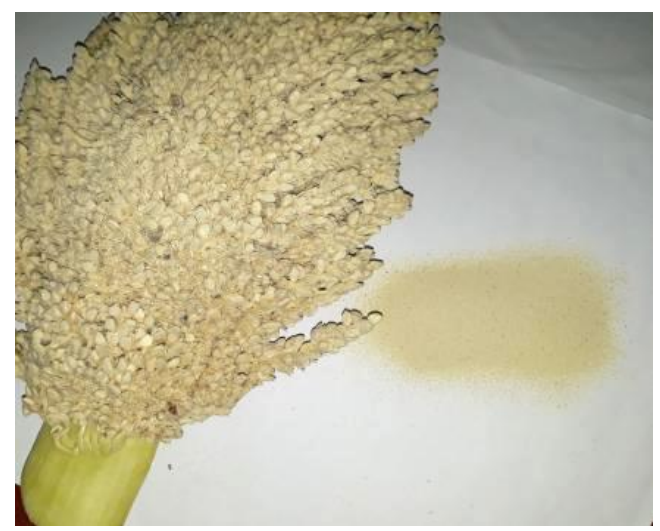

$a$

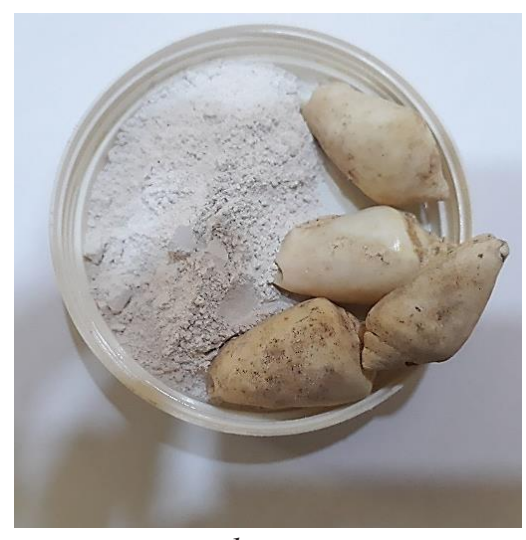

$b$

Fig. 1. Micro-fillers of: $a$ - pollen palm; $b$ - Seashell powder

The micro-fillers preparation of pollen palm was started by drying the pollen palm under sun rays for 4 days after being collected and separated from the pollen flower. Fig. 1 shows the produced powder of the pollen palm after being further dried using warm electric oven for 30 minutes. This is an important step to ensure that pollen palm power would not volatilize. The particle size of the pollen palm was measured by sieve 300 mesh and found to be $50 \mu \mathrm{m}$. Moreover, the seashell was washed to remove any impurities from its surface, dried and milled for 45 minutes and sieved. The particle size of seashell was $75 \mu \mathrm{m}$.

After preparing the fillers of seashell and pollen palm, the specimens' formulation was done using basis of mixture. A plastic mould of dimension $200 \times 150 \times 5 \mathrm{~mm}^{3}$ was used. Pollen palm and seashell micro-fillers were mixed carefully and mechanically stirred in a plastic jar according to composition of composite with epoxy resin, hardener, and acceleration in the ratio of 2:1 by weight. The mixture was poured into mould. The mould was allowed to be kept at room temperature for 24 hours. The specimens were taken out of the mould after 24 hours as shown in Fig. 2. After that, they were cut into different shapes and had varying dimensions according to ASTM standards for mechanical properties and water absorption testes by CNC machine as shown in Fig. 3 the detail content of different types of prepared composites are given in Table 1. In this aspect, epoxy $100 \mathrm{wt} \%$ represents the base case while other prepared composites are made from different weight percentages of seashell and pollen palm mixed with epoxy.

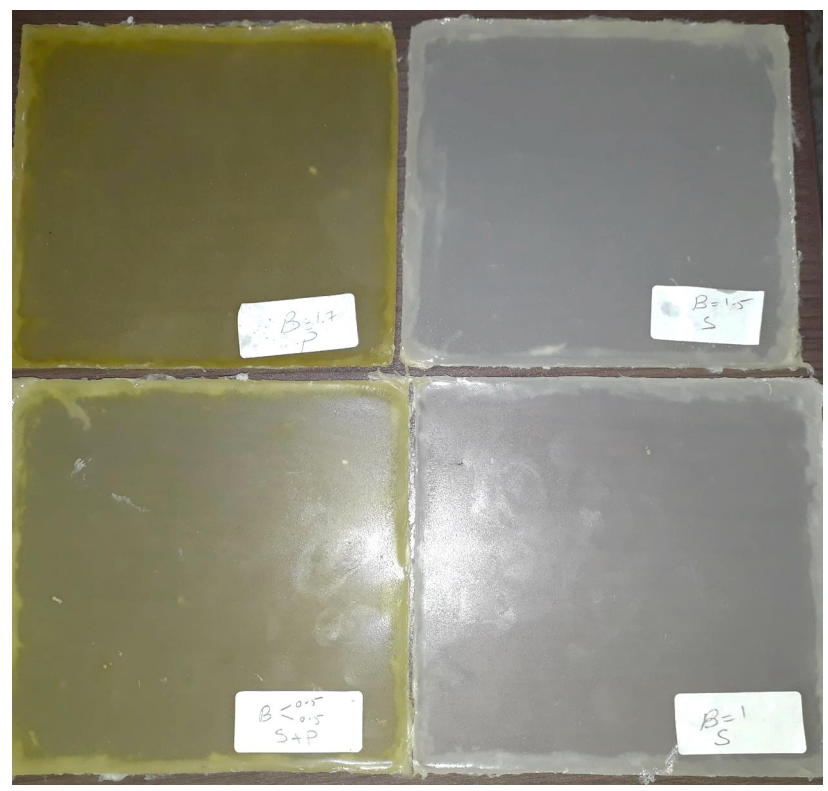

Fig. 2. The castings of four specimens 

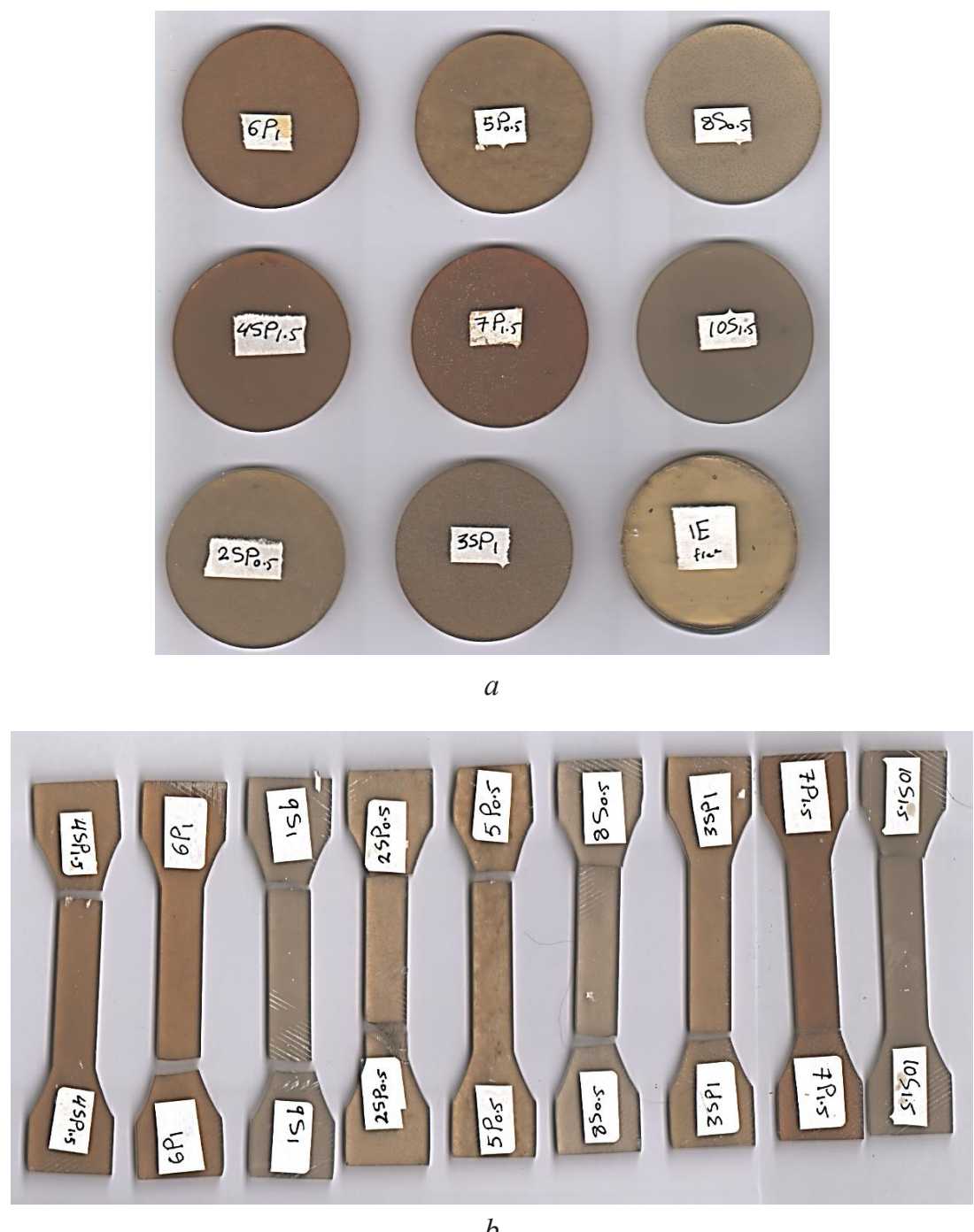

Fig. 3. Different shapes of specimens: $a$-tensile test; $b$-water absorption test

Table 1

Detail designation and composition of composites

\begin{tabular}{cccc}
\hline \multirow{2}{*}{ Type of composite } & \multicolumn{3}{c}{ Designed compositions } \\
\cline { 2 - 4 } & Epoxy wt \% & Pollen palm wt \% & Seashell wt \% \\
\hline E (base case) & 100 & 0 & 0 \\
SP0.5 & 99.5 & 0.25 & 0.25 \\
SP1 & 99 & 0.5 & 0.5 \\
SP1.5 & 98.5 & 0.75 & 0.75 \\
P0.5 & 99.5 & 0.5 & 0 \\
P1 & 99 & 1 & 0 \\
P1.5 & 98.5 & 1.5 & 0 \\
S0.5 & 99.5 & 0 & 0.5 \\
S1 & 99 & 0 & 1 \\
S1.5 & 98.5 & 0 & 1.5
\end{tabular}

\section{2. Mechanical properties}

The mechanical properties of flexural, impact, tensile and hardening tests were achieved on the epoxy/(pollen palm and seashell) micro-fillers composites. In this regard, the influence of 
different weight ratios of epoxy/micro fillers (pollen palm and seashell) at practical size of $50,75 \mu \mathrm{m}$, respectively, was assessed. For each test nine specimens were used. The flexural tests were carried out using three-point bend, according to ASTM 790. Impact tests were carried out according to ASTM D256 using the IZOD impact tester. The universal test machine (JIANQIAO) was used for tensile tests, according to ASTM D638. The hardness test impalement according to ASTM shore D methods.

The water absorption of composite materials is a very important property that can be determined by water absorption test [16]. The dimensions of the specimens and the procedure of testing were carried out according to ASTM D570-98 standard. The specimen size was $3.2 \mathrm{~mm}$ (1/8 inch) thickness and 50.8 (2 inch) in diameter. The initial weight of the specimens was measured and recorded by electronic-weight scale. Each of the specimens was immersed in normal water for 7 days and weighted orderly at (24, 48, 96, 120, 144 and 168 hours) after removing the moisture or surface with a clean dry cloth or (tissue paper) [17]. The water absorption percentage of composite is determined by (1),

$$
\text { Water absorption }=\frac{\text { final weight }- \text { initial weight }}{\text { initial weight }} \times 100 \% .
$$

\section{3. Grey Relational Analysis method (GRG)}

In multi-response optimization problems, the influence and relationship between different parameters are complex and not clear. Basically, there are several optimization methods such as Grey Relational Analysis, TOPSIS method, WASPAS etc. that used to determine the rank of special results that would entirely highlight the most ideal one. This research has employed the Grey Relational Analysis method to carry out a multi-objective optimization in order to the mechanical properties of composites and minimize the water absorption property. Specifically, this method is characterized by using Grey Relational Grad (GRG) that converts a multi-objectives optimization problem into a single objective problem called a single relational grade [18]. The theoretical principles of GRA method are represented in several steps as follows.

Due to the variation of given data, it is firstly important to normalize the data in order to reduce its variability and unify its units. In this regard, data normalization is specifically deriving suitable values from the original one to build an array between 0 to 1 [19]. The following formula is used to normalize the data and scale it into an acceptable range,

$$
x_{i(k)}^{*}=\frac{\max \left[x_{i}(k)\right]-x_{i}(k)}{\max \left[x_{i}(k)\right]-\min \left[x_{i}(k)\right]}
$$

$x_{i(k)}^{*}$ denotes the sequence after data preprocessing; $i=1, \ldots, m ; k=1, \ldots, n$ where $m$ and $n$ are the numbers of experimental data and responses, respectively.

$\operatorname{Max} x_{i(k)}$ and $\min x_{i(k)}=$ the largest value and smallest value of data, respectively where $x$ is the desired value [19].

However, a high-quality normalized value of $x_{i(k)}^{*}$ can be presented in (3),

$$
x_{i(k)}^{*}=\frac{x_{i(k)}-\min \left[x_{i(k)}\right]}{\max \left[x_{i(k)}\right]-\min \left[x_{i(k)}\right]} .
$$

This step is characterized by calculation of the grey relation coefficient $\xi_{i(k)}$ as depicted in (4),

$$
\xi_{i(k)}=\frac{\Delta_{\min }+\xi \Delta_{\max }}{\Delta_{o i}(k)+\xi \Delta_{\max }}
$$

$\Delta_{o i}=$ the deviation sequence of the reference sequence $x_{o(k)}$ and the comparability sequence $\left(x_{i(k)}\right)$; $\Delta_{\min }$ and $\Delta_{\max }=$ the minimum and maximum values of the absolute differences $\Delta_{\mathrm{o} i}$ of all comparing sequences, respectively; $\xi_{i(k)}=$ implies the identification parameter that lies between 0 to 1 . 
The Grey Relational Grade $\left(\mathrm{GRG}_{i}\right)$ for $i$-th experiment is estimated at this step as in (5):

$$
\mathrm{GRG}_{i}=\frac{1}{n} \sum_{k=1}^{n} \xi_{i}(k) .
$$

The symbol $\mathrm{n}$ is the number of responses [20], where GRG can denote the relationship between the reference sequence and the comparison sequence which may represent.

\section{Results and discussion}

\section{1. Mechanical properties}

\section{1. 1. Flexural strength}

The flexural strength property is used to measure the necessary force to bend the composites sample under three-point loading condition. Fig. 4 shows the flexural strength of different composite contents and base case of epoxy. It is easy to notice that composite S1 has the maximum flexural strength of 64.42 MPa compared to other considered filled and unfilled composites. The high degree of compatibility between polymer and filler would interpret the high flexural strength. More importantly, adding pollen palm or seashell fillers at $1.5 \mathrm{wt} \%$ would increase the flexural strength if compared to the original value of epoxy as a base case. However, adding only $0.5 \mathrm{wt} \%$ of filler content of pollen palm and seashell would reduce the flexural strength. Seemingly, increasing the wt \% content of filler to epoxy would preserve a uniform distribution of micro-filler materials that entirely increases the interface adhesion between polymer and micro-filler. However, a destruction of bonding between filler and epoxy is expected only at low content of filler $(0.5 \mathrm{wt} \%)$.

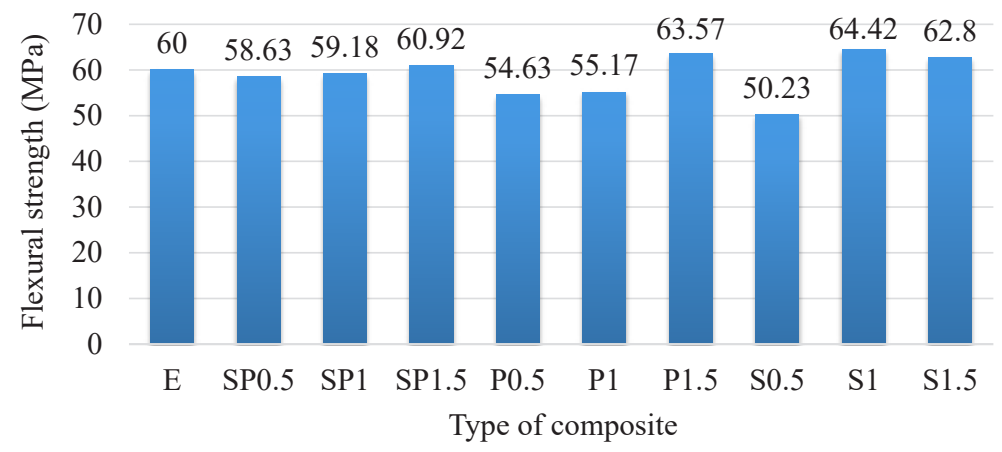

Fig. 4. Flexural strength of different epoxy composites of different wt $\%$ of micro fillers

\section{1. 2. Impact strength}

Impact strength is a property that assesses the ability of a specified material to tackle a sudden applied load before getting fractured. This is always measured by energy units. In this regard, the influence of adding micro-fillers at different weight content on the impact strength is depicted in Fig. 5.

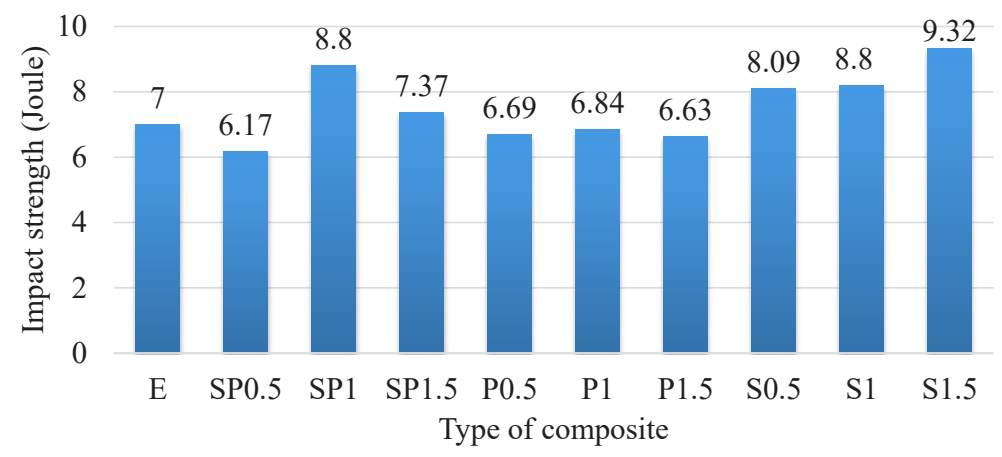

Fig. 5. Impact strength of different epoxy composites of different wt $\%$ of micro fillers 
It is not complicated to observe that seashell composite of $1.5 \mathrm{wt} \%$ has the utmost capacity to withstand an external load as it can absorb a maximum energy of 9.32 joule followed by SP1 that entails 8.8 joule. However, pollen palm composites at all weight content have surprisingly reduced the impact strength compared to original base case of epoxy $(E)$. Seemingly, seashell filler has maintained a high level of bonding strength between the polymer and filler molecules besides an increase of flexibility that resulted in a high capacity of absorbing energy that consequently retards early cracks. However, pollen palm is a type of natural cellulose that characterize by its porous with a large volume of internal voids.

\section{1. 3. Tensile strength}

Tensile strength is an important property used to measure the capacity of material against tensile test loading. This in turn would allocate the maximum force per cross-sectional area of tensile specimens. The variation of tensile strength against wt $\%$ of different filler contents and base case of epoxy is demonstrated in Fig. 6. This in turn shows that composite S1 has the maximum tensile strength of $28.07 \mathrm{MPa}$. In this regard, adding only $1 \mathrm{wt} \%$ and $1.5 \mathrm{wt} \%$ of S1 would increase the tensile strength of base case of epoxy compared to adding other fillers that elaborated a reduction of tensile strength. Apparently, adding seashell filler would serve as a barrier against crack growth that interpret high tensile strength [16]. The characteristics of pollen palm of cellulose fiber with low modulus of electricity may interpret the reason behind reduced strength tensile of the pollen palm synthesized fillers.

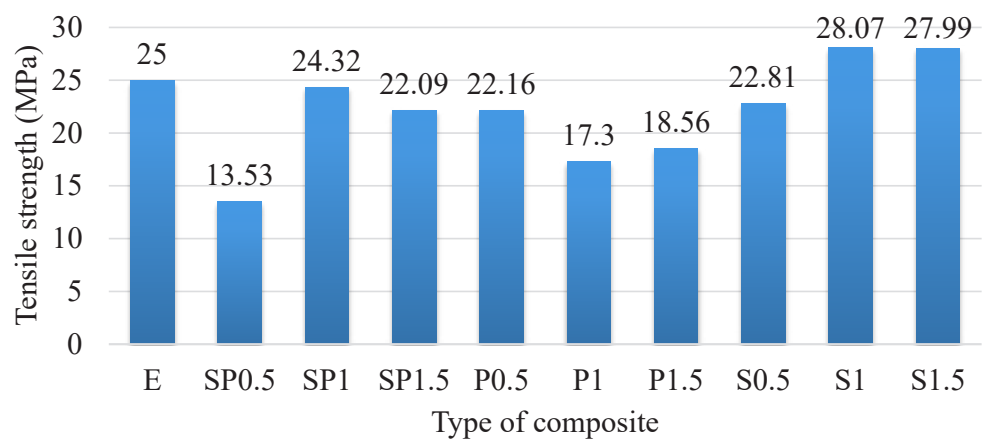

Fig. 6. Tensile strength of different epoxy composites of different wt $\%$ of micro-fillers

\section{1. 4. Hardness}

Hardness is a critical property that used to assess the resistance against plastic deformation caused by an external mechanical depression. Shore $D$ scale is usually used to measure hardness property. This section would illustrate the influence of adding micro-fillers of pollen palm, seashell, and pollen palm-seashell to epoxy composite at different three weight content on hardness as depicted in Fig. 7.

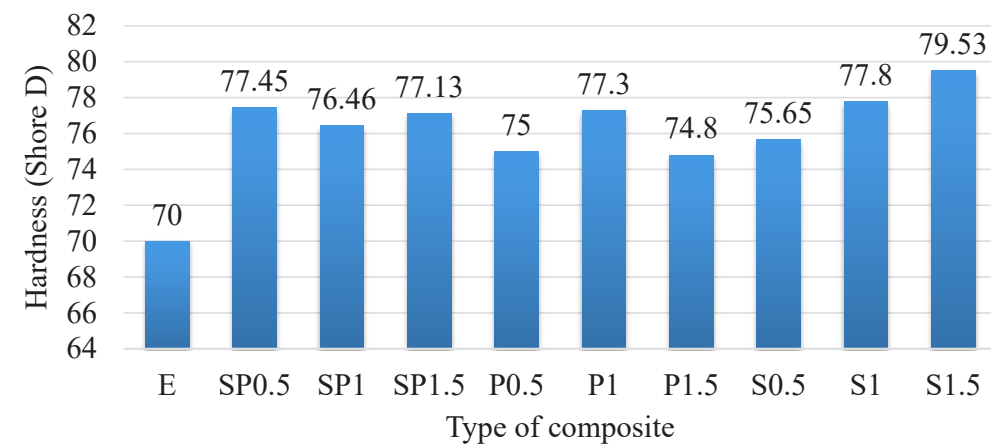

Fig. 7. Hardness of different epoxy composites of different wt \% of micro-fillers

As expected, adding fillers to epoxy would enhance hardness. However, the maximum one has been registered to composite S1.5 that hits 79.53 compared to 70 of the epoxy base case. A uniform 
dispersion of seashell inside epoxy material would interpret an increased hardness as it would reduce the distance between the molecules and increase hardness property against depression. However, it can be stated that adding filler composites of pollen palm and seashell has exhibited a significant enhancement of hardness if compared to unfilled composite of epoxy.

\section{2. Water absorption test}

Water absorption test is another important test to assess the strength of composite material as it specifies the absorption of water [17]. Fig. 8 shows the influence of different weight content of fillers added to epoxy (base case) on the water absorption of the epoxy composites. This affirmed a primitive increase of water absorption characteristic as a result to adding fillers to epoxy. More importantly, increasing the weight content of filler would enhance the water absorption for all the tested cases compared to the original one (E). However, the highest water absorption has been reported to $1.5 \mathrm{wt} \%$ of seashell filler if compared to other composites. Moreover, the results of Fig. 8 demonstrated that adding pollen palm would clearly reduce the water absorption rate for almost the weight contents. To enhance the water absorption rate of pollen palm composites, mixture of pollen palm and seashell would elevate the water absorption as depicted in Fig. 8. Therefore, there is a clear space to synthesis composites with favorable water absorption based on pollen palm and seashell fillers. It is important to realize that the seashell filler has a high content of calcium carbonate that would interpret a strong trend to absorb water and therefore has increased water absorption as a result to increasing weight percentage if compared to pollen palm.

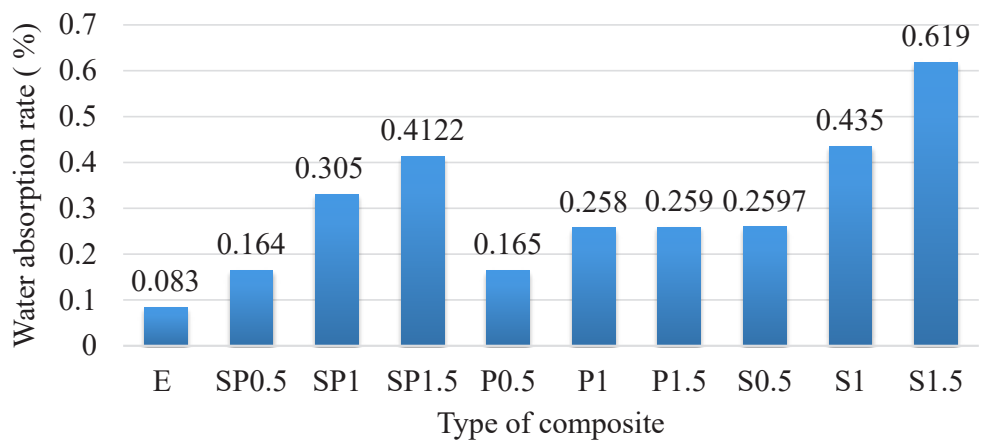

Fig. 8. Water absorption of different epoxy composites of different wt $\%$ of micro fillers

The aforementioned theoretical steps of the grey relational analysis method were used to optimize the synthesized composites. In this regard, the experimental data of the mechanical properties and water absorption property are presented in Table 2.

Table 2

Experimental results of mechanical properties and water absorption property

\begin{tabular}{cccccc}
\hline Type of composite & $\begin{array}{c}\text { Tensile Strength, } \\
\text { MPa }\end{array}$ & $\begin{array}{c}\text { Flexural } \\
\text { Strength, MPa }\end{array}$ & $\begin{array}{c}\text { Impact Strength, } \\
\text { Joules }\end{array}$ & Hardness, (Shor $\boldsymbol{D}$ ) & Water absorption, \% \\
\hline E (base case) & 25 & 60 & 7 & 70 & 0.083 \\
Sp0.5 & 13.53 & 58.63 & 6.17 & 77.45 & 0.164 \\
SP1 & 24.32 & 59.18 & 8.8 & 76.46 & 0.3305 \\
SP1.5 & 22.09 & 60.92 & 7.37 & 77.13 & 0.2469 \\
P0.5 & 22.16 & 54.63 & 6.69 & 75 & 0.165 \\
P1 & 17.30 & 55.17 & 6.84 & 77.3 & 0.258 \\
P1.5 & 18.56 & 63.57 & 6.63 & 74.8 & 0.254 \\
S0.5 & 22.81 & 50.23 & 8.09 & 75.65 & 0.2597 \\
S1 & 28.07 & 64.42 & 8.18 & 77.8 & 0.1734 \\
S1.5 & 27.99 & 62.8 & 9.32 & 79.53 & 0.176
\end{tabular}


However, the normalized data of the mechanical properties and water absorption property are given in Table 3 considering that the best values of tensile strength and water absorption are the smaller one. However, the larger values of the other properties were considered as the best one as depicted in Table 3. (1) is basically used to carry out this normalization that entailed the estimation of the data given in Table 3 that termed as the grey relational generations.

Table 3

Normalized data of mechanical properties and water absorption property

\begin{tabular}{|c|c|c|c|c|c|}
\hline \multirow{2}{*}{ Type of composite } & \multirow{2}{*}{$\begin{array}{c}\text { Tension } \\
\text { (min - the better) }\end{array}$} & \multirow{2}{*}{$\begin{array}{c}\text { Flexural } \\
\text { (max }- \text { the better) }\end{array}$} & \multirow{2}{*}{$\begin{array}{c}\text { Impact } \\
\text { (max - the better) }\end{array}$} & \multicolumn{2}{|c|}{ Hardness } \\
\hline & & & & (max - the better) & (min - the better) \\
\hline E (base case) & 0.211 & 0.689 & 0.263 & 0.000 & 1.000 \\
\hline $\mathrm{SP} 0.5$ & 1.000 & 0.592 & 0.000 & 0.782 & 0.673 \\
\hline SP1 & 0.258 & 0.631 & 0.835 & 0.678 & 0.000 \\
\hline SP1.5 & 0.411 & 0.753 & 0.381 & 0.748 & 0.338 \\
\hline P0.5 & 0.406 & 0.310 & 0.165 & 0.525 & 0.669 \\
\hline $\mathrm{P} 1$ & 0.741 & 0.348 & 0.213 & 0.766 & 0.293 \\
\hline $\mathrm{P} 1.5$ & 0.654 & 0.940 & 0.146 & 0.504 & 0.309 \\
\hline S0.5 & 0.362 & 0.000 & 0.610 & 0.593 & 0.286 \\
\hline S1 & 0.000 & 1.000 & 0.003 & 0.818 & 0.635 \\
\hline S1.5 & 0.006 & 0.886 & 1.000 & 1.000 & 0.624 \\
\hline
\end{tabular}

Where the use of mathematical expression (2), to calculate the gray relational coefficients, or the deviation sequence of the reference sequence and the comparability sequence based on the given normalized data shown in Table 2. Occasionally, the identification parameter $\xi_{i(k)}$ is taken as 0.5 in this research. The results of deviation $\Delta_{o i}$ sequence data are given in Table 4.

Table 4

The deviation sequence data $\Delta_{o i}$

\begin{tabular}{cccccc}
\hline \multirow{2}{*}{ Type of composite } & \multicolumn{5}{c}{ Evaluation of $\boldsymbol{\Delta}_{\boldsymbol{o} i}$} \\
\cline { 2 - 5 } & Tension & Flexural & Impact & Hardness & Water absorption \\
\hline E (base case) & 0.789 & 0.311 & 0.737 & 1.000 & 0.000 \\
SP0.5 & 0.000 & 0.408 & 1.000 & 0.218 & 0.327 \\
SP1 & 0.742 & 0.369 & 0.165 & 0.322 & 1.000 \\
SP1.5 & 0.589 & 0.247 & 0.619 & 0.252 & 0.662 \\
P0.5 & 0.594 & 0.690 & 0.835 & 0.475 & 0.331 \\
P1 & 0.259 & 0.652 & 0.787 & 0.234 & 0.707 \\
P1.5 & 0.346 & 0.060 & 0.854 & 0.496 & 0.691 \\
S0.5 & 0.638 & 1.000 & 0.390 & 0.407 & 0.714 \\
S1 & 1.000 & 0.000 & 0.997 & 0.182 & 0.365 \\
S1.5 & 0.994 & 0.114 & 0.000 & 0.000 & 0.376
\end{tabular}

Moreover, GRA method is specifically used to find the top ranked composite after a simple comparison with other computed ranks based on their physical properties and water absorption property. Table 5 shows the ranking of micro-filled and unfilled composites. Results clearly show that that ranking of composites are as following: Rank 1 (S1.5: Epoxy+1.5 wt \% microfiller of seashell), Rank 2 (SP0.5: Epoxy+micro-filler ( $0.25 \mathrm{wt} \%$ pollen Palm $+0.25 \mathrm{wt} \%$ seashell)), Rank 3 (s1: Epoxy+1wt \% micro-filler seashell), Rank 4 (P1.5: Epoxy+1.5 wt \% micro-filler of pollen palm), Rank 5 (E(base case): $100 \mathrm{wt} \%$ Epoxy $+0 \mathrm{wt} \%$ micro-filler), Rank 6 (SP1: Epo$\mathrm{xy}+$ micro-filler of $(0.5 \mathrm{wt} \%$ pollen Palm $+0.5 \mathrm{wt} \%$ seashell)), Rank 7 (SP1.5: Epoxy+micro-filler 
of (0.75 wt \% pollen palm +0.75 wt \% seashell)), Rank 8 (P1: 1 wt \% micro-filler pollen palm), Rank 9 (P0.5: Epoxy+0.5 wt \% pollen palm micro-filler), Rank 10 (S0.5: Epoxy+0.5 wt \% seashell micro-filler). More importantly, the analysis of those ranks affirmed that adding of $1.5 \mathrm{wt} \%$ seashell micro-filler to epoxy composite would elaborate the highest rank that means prepared composite of high-mechanical properties and minimum water absorption. However, SP0.5 has obtained the second highest rank with almost mechanical properties and water absorption property closed to S1.5.

Table 5

Grey relational coefficient and relational grade values

\begin{tabular}{cccccccc}
\hline Type of composite & Tension & Flexural & Impact & Hardness & Water absorption & GRG & Rank \\
\hline E (base case) & 0.388 & 0.616 & 0.404 & 0.333 & 1.000 & 0.548 & 5 \\
SP0.5 & 1.000 & 0.551 & 0.333 & 0.696 & 0.604 & 0.637 & 2 \\
SP1 & 0.403 & 0.575 & 0.752 & 0.608 & 0.333 & 0.534 & 6 \\
SP1.5 & 0.459 & 0.670 & 0.447 & 0.665 & 0.430 & 0.534 & 7 \\
P0.5 & 0.457 & 0.420 & 0.375 & 0.513 & 0.601 & 0.473 & 9 \\
P1 & 0.659 & 0.434 & 0.388 & 0.681 & 0.414 & 0.515 & 8 \\
P1.5 & 0.591 & 0.893 & 0.369 & 0.502 & 0.420 & 0.555 & 4 \\
S0.5 & 0.439 & 0.333 & 0.561 & 0.551 & 0.412 & 0.459 & 10 \\
S1 & 0.333 & 1.000 & 0.334 & 0.734 & 0.578 & 0.596 & 3 \\
S1.5 & 0.335 & 0.814 & 1.000 & 1.000 & 0.571 & 0.744 & 1
\end{tabular}

The limitations are inherent in this study:

- the sample casting process and all tests were carried out at a temperature of $25{ }^{\circ} \mathrm{C}$ and a humidity of approximately $5 \%$;

- the materials added in the research (pollen+seashells) as a filler are $100 \%$ natural materials free of impurities and moisture;

- the method of drying the natural materials added in the research was done by using sunlight in the summer and then using a nicely warm oven to prevent burning and thus preserving the properties of the basic components of the natural materials;

- the results are related to the weight ratios as well as the grain size of the filler in the current research.

The directions for the development of this study:

- expanding the current study by applying it to include various thermosetting composites in order to compare the results;

- study of thermal and acoustic insulation of the composites of the current study;

- studying wider ranges of different weight ratios and different particle size to the added natural materials as a filler and their effect on the mechanical properties composites.

\section{Conclusions}

This research demonstrated the fabrication of different epoxy and micro-additives of seashell and pollen palm at different weight percentages. The mechanical properties and water absorption property were compared against the original base case of epoxy composite. Specifically, it is found that micro-additive filled composites show excellent tensile strength compared to unfilled composites where the highest tensile strength has been obtained with a mixture of $1.5 \mathrm{wt} \%$ of seashell-based epoxy composite. Also, a composite of epoxy and $1 \mathrm{wt} \%$ seashell has observed the highest flexural strength. The highest impact strength obtained with $1.5 \mathrm{wt} \%$ of seashell filler of 9.32 Joules compared to 7 Joules of unfilled composites. Moreover, the hardness property was clearly enhanced for all the prepared composites compared to epoxy unfilled composite. However, the water absorption property was increased in all cases filled compared with unfilled epoxy composite. Therefore, the Gray Relational Analysis optimization method used to locate the highest ranked composite. This is specially carried out via multi-objective optimization of 
maximum mechanical properties and minimum water absorption property. This in turn investigated that the epoxy and $1.5 \mathrm{wt} \%$ of seashell composite has the highest rank compared to other filler composites.

This research has successfully suggested the fabrication of new effective and environment friendly filled-epoxy composites of recycling seashell waste and cellulose pollen palm that entailed with enhanced mechanical properties and water absorption property.

\section{Acknowledgement}

The authors are grateful to the management of Middle Technical University-Baghdad-Iraq for the supporting in research.

\section{References}

[1] Herrera-Franco, P. J., Aguilar-Vega, M. de J. (1997). Effect of fiber treatment on the mechanical properties of LDPE-henequen cellulosic fiber composites. Journal of applied polymer science, 65 (1), 197-207. doi: https://doi.org/10.1002/ (sici)1097-4628(19970705)65:1<197::aid-app24>3.0.co;2-\#

[2] Kowalczyk, M., Piorkowska, E., Kulpinski, P., Pracella, M. (2011). Mechanical and thermal properties of PLA composites with cellulose nanofibers and standard size fibers. Composites Part A: Applied Science and Manufacturing, 42 (10), $1509-1514$. doi: https://doi.org/10.1016/j.compositesa.2011.07.003

[3] Pandey, J. K., Takagi, H., Nakagaito, A. N., Saini, D. R., Ahn, S.-H. (2012). An overview on the cellulose based conducting composites. Composites Part B: Engineering, 43 (7), 2822-2826. doi: https://doi.org/10.1016/j.compositesb.2012.04.045

[4] Wollerdorfer, M., Bader, H. (1998). Influence of natural fibres on the mechanical properties of biodegradable polymers. Industrial Crops and Products, 8 (2), 105-112. doi: https://doi.org/10.1016/s0926-6690(97)10015-2

[5] Keller, A. (2003). Compounding and mechanical properties of biodegradable hemp fibre composites. Composites Science and Technology, 63 (9), 1307-1316. doi: https://doi.org/10.1016/s0266-3538(03)00102-7

[6] Odusanya, A. A., Bolasodun, B., Madueke, C. I. (2014). Property evaluation of sea shell filler reinforced unsaturated polyester composite. International Journal of Scientific \& Engineering Research, 5 (11), 1343-1349. Available at: https:/www.ijser.org/ researchpaper/Property-Evaluation-of-Sea-shell-Filler-Reinforced-Unsaturated.pdf

[7] Pokroy, B., Fitch, A. N., Lee, P. L., Quintana, J. P., Caspi, E. N., Zolotoyabko, E. (2006). Anisotropic lattice distortions in the mollusk-made aragonite: A widespread phenomenon. Journal of Structural Biology, 153 (2), 145-150. doi: https://doi.org/ 10.1016/j.jsb.2005.10.009

[8] Meyers, M. A., Chen, P.-Y., Lin, A. Y.-M., Seki, Y. (2008). Biological materials: Structure and mechanical properties. Progress in Materials Science, 53 (1), 1-206. doi: https://doi.org/10.1016/j.pmatsci.2007.05.002

[9] Lu, T., Jiang, M., Jiang, Z., Hui, D., Wang, Z., Zhou, Z. (2013). Effect of surface modification of bamboo cellulose fibers on mechanical properties of cellulose/epoxy composites. Composites Part B: Engineering, 51, 28-34. doi: https://oi.org/10.1016/ j.compositesb.2013.02.031

[10] Anand, P., Anbumalar, V. (2015). Mechanical Properties of Cellulose-filled Epoxy Hybrid Composites Reinforced with Alkali-treated Hemp Fiber. Polymer Korea, 39 (1), 46-55. doi: https://doi.org/10.7317/pk.2015.39.1.46

[11] Patel, V. K., Dhanola, A. (2016). Influence of CaCO3, A12O3, and TiO2 microfillers on physico-mechanical properties of Luffa cylindrica/polyester composites. Engineering Science and Technology, an International Journal, 19 (2), 676-683. doi: https:// doi.org/10.1016/j.jestch.2015.10.005

[12] Melo, P. M. A., Macêdo, O. B., Barbosa, G. P., Ueki, M. M., Silva, L. B. (2019). High-density polyethylene/mollusk shell-waste composites: effects of particle size and coupling agent on morphology, mechanical and thermal properties. Journal of Materials Research and Technology, 8 (2), 1915-1925. doi: https://doi.org/10.1016/j.jmrt.2019.01.008

[13] Chong, M. H., Chun, B. C., Chung, Y.-C., Cho, B. G. (2005). Fire-retardant plastic material from oyster-shell powder and recycled polyethylene. Journal of Applied Polymer Science, 99 (4), 1583-1589. doi: https://doi.org/10.1002/app.22484

[14] Kaseem, M., Ko, Y. G. (2016). Melt Flow Behavior and Processability of Polylactic Acid/Polystyrene (PLA/PS) Polymer Blends. Journal of Polymers and the Environment, 25 (4), 994-998. doi: https://doi.org/10.1007/s10924-016-0873-5

[15] Datesproduction report for the year 2019. Central Statistical Organization Iraq SCO. Ministry of Planning. Iraq. Available at: http://cosit.gov.iq/documents/agriculture/agri_other/full\%20reports/\%D8\%AA\%D9\%82\%D8\%B1\%D9\%8A\%D8\%B1\%20 \%D8\%A7\%D9\%86\%D8\%AA\%D8\%A7\%D8\%AC\%20\%D8\%A7\%D9\%84\%D8\%AA\%D9\%85\%D9\%88\%D8\%B1\%202019.pdf

[16] Munthoub, D. I., Rahman, W. A. W. A. (2011). Tensile and Water Absorption Properties of Biodegradable Composites Derived from Cassava Skin/Polyvinyl Alcohol with Glycerol as Plasticizer. Sains Malaysiana, 40 (7), 713-718. Available at: http:// journalarticle.ukm.my/2544/1/07_Dayangku_Intan.pdf 
[17] Deo, C., Acharya, S. K. (2010). Effect of Moisture Absorption on Mechanical Properties of Chopped Natural Fiber Reinforced Epoxy Composite. Journal of Reinforced Plastics and Composites, 29 (16), 2513-2521. doi: https:/doi.org/ 10.1177/0731684409353352

[18] Ajith Arul Daniel, S., Pugazhenthi, R., Kumar, R., Vijayananth, S. (2019). Multi objective prediction and optimization of control parameters in the milling of aluminium hybrid metal matrix composites using ANN and Taguchi -grey relational analysis. Defence Technology, 15 (4), 545-556. doi: https://doi.org/10.1016/j.dt.2019.01.001

[19] Panda, A., Sahoo, A. K., Rout, A. K. (2016). Multi-attribute decision making parametric optimization and modeling in hard turning using ceramic insert through grey relational analysis: A case study. Decision Science Letters, 581-592. doi: https://doi.org/ $10.5267 / j . d s 1.2016 .3 .001$

[20] Haq, A. N., Marimuthu, P., Jeyapaul, R. (2007). Multi response optimization of machining parameters of drilling Al/SiC metal matrix composite using grey relational analysis in the Taguchi method. The International Journal of Advanced Manufacturing Technology, 37 (3-4), 250-255. doi: https://doi.org/10.1007/s00170-007-0981-4

Received date 29.07.2021

Accepted date 08.11.2021

Published date 10.01.2022
(C) The Author(s) 2021

This is an open access article under the Creative Commons CC BY license

How to cite: Khalaf, A. A., Abed, S. A., Alkhfaji, S. S., Al-Obaidi, M. A., Hanon, M. M. (2022). The effect of adding natural materials waste on the mechanical properties and water absorption of epoxy composite using grey relations analysis. EUREKA: Physics and Engineering, 1, 131-142. doi: https://doi.org/10.21303/2461-4262.2022.001952 